\title{
Why distinguish between ulcerative colitis and Crohn's disease?
}

\author{
DANIEL RACHMILEWITZ, MD
} T IS IMPORTANT TO DISTINGUISH BETWEEN ULCERATIVE COlitis and Crohn's disease because they differ in their clinical course, in their complications and, thus, in their medical and surgical management. Crohn's disease may affect any part of the gastrointestinal tract from the mouth to the anus while ulcerative colitis affects only the colon. Therefore, there is a point in distinguishing between these two diseases, mainly in patients with colonic involvement. The etiology of both ulcerative colitis and Crohn's disease is not yet known. Infectious, immunologic, genetic, environmental, allergic and psychogenic etiologic factors have been suggested but none has been proven, so far. Most probably, there is no one common etiology to account for both diseases, but elucidation of the etiologic factor may pave the road to more satisfactory treatment.

In the last decade much effort has been devoted to research on the pathogenesis of the inflammatory response in inflammatory bowel disease. The possible role of several soluble mediators was suggested. It is not surprising that in all instances, when tested, the same mediators were found to be involved in the pathogenesis of ulcerative colitis and Crohn's disease. The colonic generation of eicosanoids - prostaglandins and leukotrienes - was shown to be enhanced in the active phase of both diseases (1). Colonic interleukin-1 generation is stimulated to the same extent in both diseases (2). Platelet activating factor production tested, so far only in

Hadassah University Hospital, Jerusalem, Israel

Correspondence and reprints: Dr Daniel Rachmilewitz, Hadassah

Medical Organization, Hadassah University Hospital, PO Box 24035 ,

IL 91240, Jerusalem, Israel

Received for publication March 1, 1989. Accepted March 31, 1989 ulcerative colitis, was found to be stimulated (3) and there is no reason to assume that in Crohn's disease its production should not be stimulated.

The establishment of the mediators involved in the pathogenesis of both diseases elucidated the mechanism most probably responsible for the therapeutic efficacy of the drugs used at present. Because in both diseases the same mediators are involved, it is not unexpected that similar medical strategies are employed. Steroids, which inhibit the formation of all mediators, are the most effective agents to control a flare-up. Sulfasalazine and its active moiety, 5-aminosalicylic acid (5-ASA), also affect the formation of all mediators known at present and, thus, are effective in the control of mild to moderate, active ulcerative colitis and in the maintenance of ulcerative colitis in remission.

As sulfasalazine is cleaved to its two components only in the colon and because the therapeutic effect of its active moiety, 5-ASA is topical, there is no point in using it in Crohn's disease patients without colonic involvement. The development of oral enteric coated slow-release forms of 5-ASA, of 5-ASA azo linked to nontoxic vehicles and of 5-ASA dimers that are split by intestinal bacteria, provides the excess of free topical 5-ASA to involved segments in the ileum as well as in the colon. Preliminary data from a double-blind study indicate that 5-ASA is superior to placebo in preventing relapses in Crohn's disease patients. Controlled trials on the efficacy of 5-ASA in the handling of active Crohn's disease are now in progress and their results still pending.

It is important to distinguish between the two diseases when the possible use of immunosuppressive drugs is raised. These drugs have been shown, in Crohn's disease, to have steroid 
sparing effect, to heal enteric and perianal fistula and ameliorate other features of the disease (4). In ulcerative colitis they may have steroid sparing effects, though this has never been properly proved. Metronidazole is another example of a drug shown to heal perianal lesions in Crohn's disease and to be beneficial in the general management of Crohn's colitis and ileocolitis (5), but has no effect in ulcerative colitis. The two diseases also differ with respect to the effect of nutritional therapy. Parenteral nutrition has a valuable adjunctive role in handling obstruction, fistulization and malnutrition in Crohn's disease. Enteral nutrition with elemental diet is also effective in certain Crohn's disease patients, whereas none of these regimens has any benefit in ulcerative colitis.

Another important reason for distinguishing between Crohn's colitis and ulcerative colitis is whenever surgery has to be considered. In general, surgery is performed in Crohn's disease only because of complications as, unfortunately, after resections and especially following anastomosis, Crohn's disease usually recurs. In ileitis, the recurrence is usually proximal to the anastomosis and, in colitis, on either side of the anastomosis. There is a steady rise in the cumulative postoperative incidence of recurrence with every passing year following surgery (6). On the other hand, in ulcerative colitis, total colectomy guarantees cure and the disease will never recur in any other part of the intestine. With the latest development of sphincter saving operations, which allow more natural defecation, ulcerative colitis patients have an attractive option to rid themselves of the disease, not only because of severe complications, such as perforation or bleeding, but also in case of medical intractability.

It was previously believed that there is increased incidence of cancer in ulcerative colitis but not in Crohn's disease. However, it is now apparent that there is also increased incidence of gastrointestinal cancer in Crohn's disease patients (7). Two- thirds of the cancers in Crohn's disease occur in grossly diseased segments of the bowel and the remaining third in uninvolved parts along the gastrointestinal tract. Increased incidence of squamous cell carcinoma in the anus and vulva have also been reported (7). Although still in dispute, many recommend and perform colonoscopic surveillance for dysplasia in patients with longstanding ulcerative colitis. Experience is not uniform but up to $50 \%$ association of occult malignancy with high grade dysplasia has been reported (8). Surveillance for dysplasia in Crohn's colitis is not popular yet, but increased index of suspicion is highly recommended.

\section{REFERENCES}

1. Donowitz M. Arachidonic acid metabolites and their role in inflammatory bowel disease. An update requiring addition of a pathway. Gastroenterology 1985;88:5080-7.

2. Ligumsky M, Simon PL, Karmeli F, Rachmilewitz D. Interleukin-1. Possible mediator of the inflammatory reponse in ulcerative colitis. Gastroenterology 1988;94:263. (Abst)

3. Eliakim R, Karmeli F, Razin E, Rachmilewitz D. Role of platelet activating factor in ulcerative colitis. Gastroenterology 1988;95:1167-73.

4. Present DH, Korelitz BI, Wisch N, et al. Treatment of Crohn's disease with 6-mercaptopurine: A long-term randomized double-blind study. N Engl J Med 1980;302:981.

5. Ursing B, Alm T, Barany F, et al. Comparative study of metronidazole and sulphasalazine for active Crohn's disease: The Cooperative Crohn's Disease Study in Sweden. Gastroenterology 1982;83:541-9.

6. Sachar DB, Wolfson DM, Greenstein AJ, et al. Risk factors for postoperative recurrence in Crohn's disease. Gastroenterology 1983;85:917-21.

7. Greenstein AJ, Sachar DB, Smith H, et al. Patterns of neoplasia in Crohn's disease and ulcerative colitis. Cancer 1980;46:403-7.

8. Rosenstock E, Farmer RG, Petros P, et al. Surveillance for colonic carcinoma in ulcerative colitis. Gastroenterology 1985;89:1342-6. 


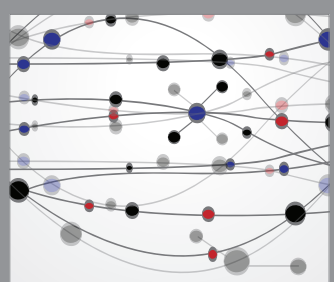

The Scientific World Journal
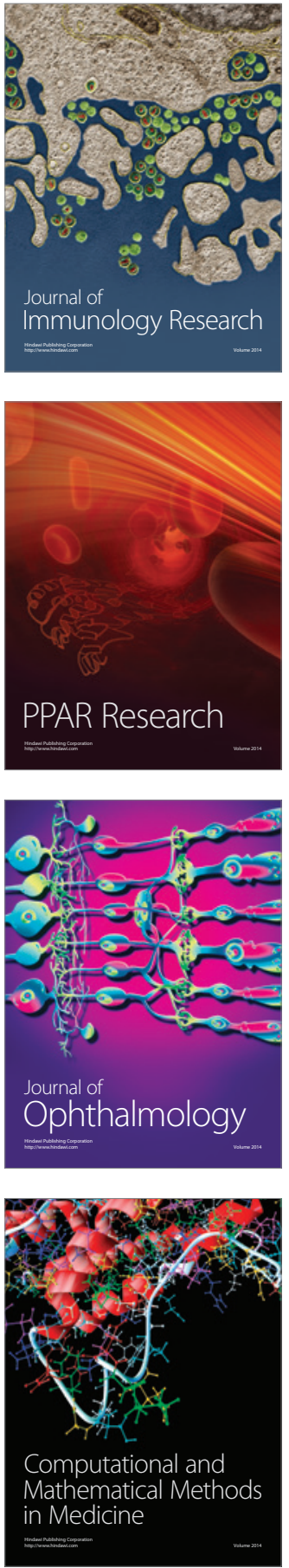

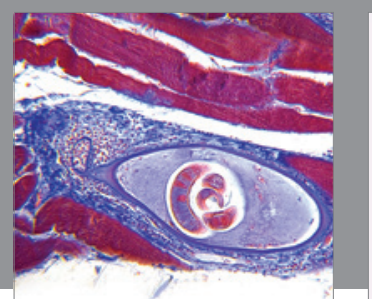

Gastroenterology Research and Practice

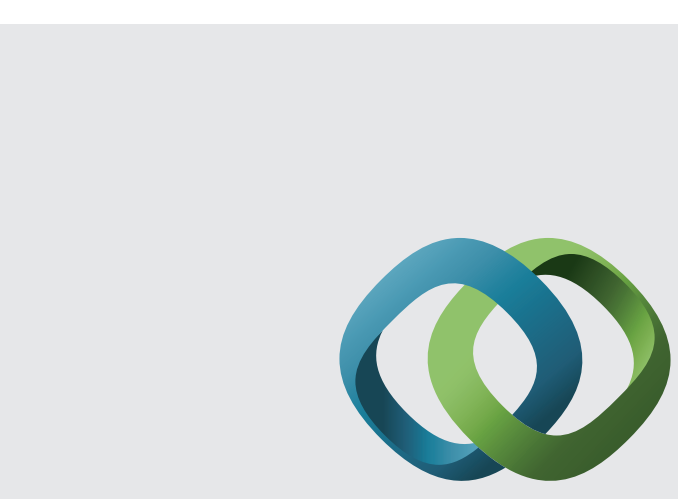

\section{Hindawi}

Submit your manuscripts at

http://www.hindawi.com
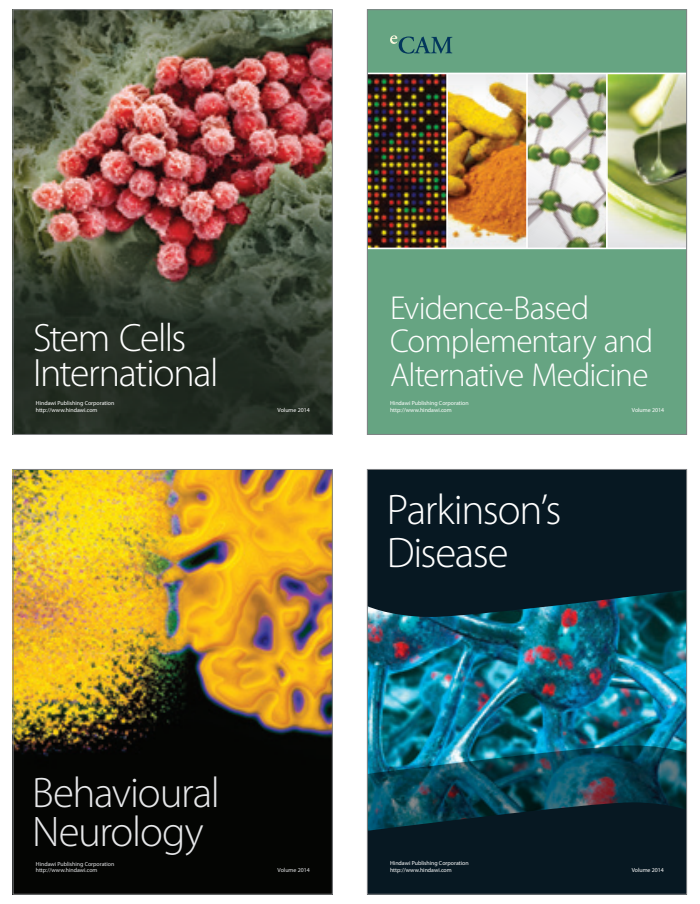
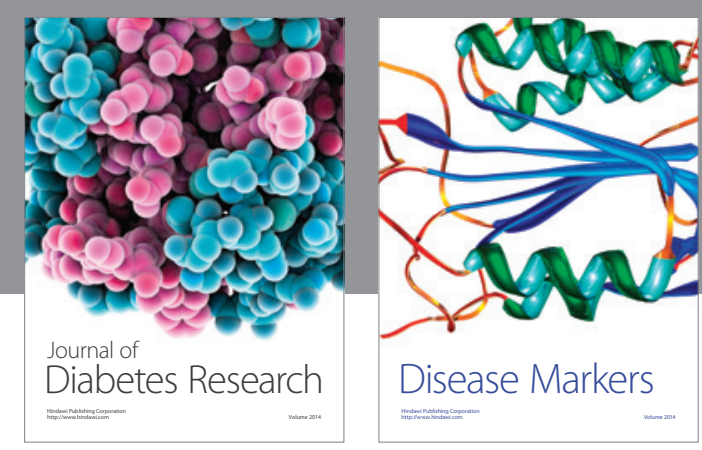

Disease Markers
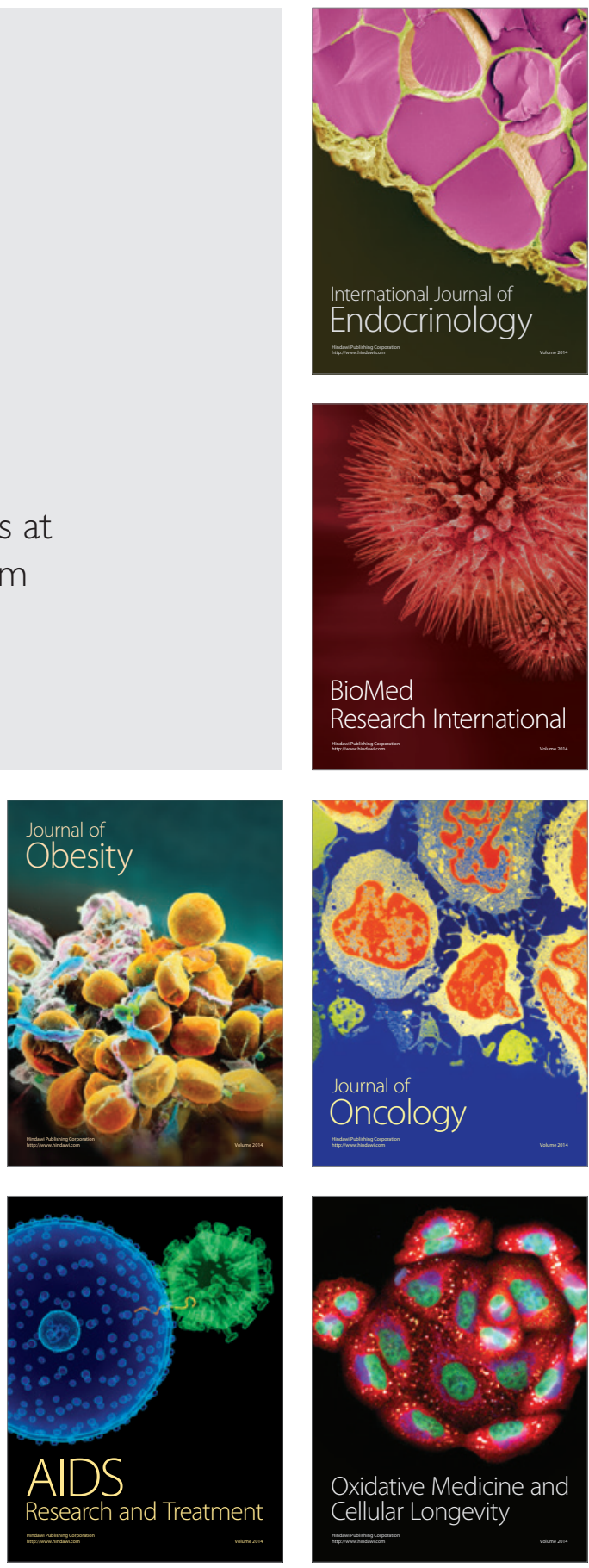